\title{
INFLUÊNCIA DAS REDES SOCIAIS DE APOIO PARA NUTRIZES ADOLESCENTES NO PROCESSO DE AMAMENTAÇÃO*
}

Verônica de Azevedo Mazza', Regina Célia Tanaka Nunes²,Rafaela Zilli Palmeiro Tararthuch³, Ana Maria Cosvoski Alexandre ${ }^{4}$,Jaqueline Vicentin Patel ${ }^{5}$

'Enfermeira. Doutora em Enfermagem. Universidade Federal do Paraná. Curitiba, PR, Brasil.

2Enfermeira. Mestre em Enfermagem. Hospital de Clínicas da Universidade Federal do Paraná. Curitiba, PR, Brasil.

${ }^{3}$ Enfermeira. Hospital Vitória Curitiba. Curitiba, PR, Brasil.

${ }^{4}$ Enfermeira. Mestre em Enfermagem. Prefeitura Municipal de Curitiba. Curitiba, PR, Brasil.

${ }^{5}$ Enfermeira. Prefeitura Municipal de Colombo. Colombo, PR, Brasil.

RESUMO: Objetivou-se investigar a influência das redes sociais de apoio no processo de amamentação de nutrizes adolescentes. Pesquisa exploratória de abordagem qualitativa, realizada em município da Região Metropolitana de Curitiba, em três Unidades de Saúde com Estratégia de Saúde da Família, no período de setembro à outubro de 2011. Foram entrevistadas nove adolescentes por meio de entrevista semiestruturada e os dados analisados por análise categorial temática. Elencaram-se duas categorias: Influência da Rede Social de Apoio Primária e Influência da Rede Social de Apoio Secundária. A Rede Primária é caracterizada por familiares e pessoas próximas, com especial participação das mulheres. As instituições e profissionais da saúde compõem a rede secundária, esta direcionada para a educação em saúde e incentivo à prática do aleitamento materno. A interação entre os profissionais, nutriz e sua família é importante, pois propicia ações mais eficazes para a promoção do aleitamento materno, em consonância com a realidade.

DESCRITORES: Aleitamento materno; Enfermagem; Apoio social; Família.

\section{INFLUENCE OF SOCIAL SUPPORT NETWORKS FOR ADOLESCENT BREASTFEEDING MOTHERS IN THE PROCESS OF BREASTFEEDING}

\begin{abstract}
The aim was to investigate the influence of the social support networks on the process of breast-feeding among adolescent mothers who are breast-feeding. This is an exploratory study with a qualitative approach undertaken in a municipality in the metropolitan region of Curitiba, in three Health Centers with Family Health Strategy, in the period September-October 2011. Nine adolescents were interviewed using semi-structured interviews, and the data were analyzed using thematic categorical analysis. Two categories were listed: Influence of the Primary Social Support Network, and Influence of the Secondary Social Support Network. The Primary Network is characterized by family members and close persons, with special participation from the women. The health institutions and professionals make up the secondary network, which is directed towards health education and encouragement for the practice of breast-feeding. The interaction between the professionals, the breast-feeding mother and her family is important, as it leads to more efficacious actions for the promotion of breast-feeding, in accordance with the context. DESCRIPTORS: Breast-feeding; Nursing; Social support; Family.
\end{abstract}

\section{INFLUENCIA DE LAS REDES SOCIALES DE APOYO PARA NUTRICES ADOLESCENTES EN EL PROCESO DE AMAMANTAMIENTO}

RESUMEN: El objetivo de este estúdio fue investigar la influencia de las redes sociales de apoyo en el proceso de amamantamiento de nutrices adolescentes. Investigación exploratoria de abordaje cualitativo, realizada en municipio de la Región Metropolitana de Curitiba, en tres Unidades de Salud con Estrategia de Salud de la Familia, en el periodo de septiembre a octubre de 2011. Fueron entrevistadas nueve adolescentes por medio de entrevista semiestructurada y los datos fueron examinados por análisis categorial temático. Resultaron dos categorías: Influencia de la Red Social de Apoyo Primaria e Influencia de la Red Social de Apoyo Secundaria. La Red Primaria es formada por familiares y personas próximas, con especial participación de las mujeres. Las instituciones y profesionales de la salud componen la red secundaria, esta direccionada para la educación en salud e incentivo a la práctica del amamantamiento materno. La interacción entre los profesionales, nutriz y su familia es importante, pues propicia aciones más efectivas para la promoción del amamantamiento materno, en consonancia con la realidad. DESCRIPTORES: Amamantamiento materno; Enfermería; Apoyo social; Familia.

*Os resultados desta pesquisa fazem parte de monografia de conclusão de curso da graduação em Enfermagem apresentada à Universidade Federal do Paraná em 2011.

Recebido: $13 / 11 / 2013$ Finalizado: $15 / 03 / 2014$

Autor correspondente:

Verônica de Azevedo Mazza

Universidade Federal do Paraná

Av. Prof. Lothário Meissner, 632. Curitiba, PR, Brasil.

E-mail: mazzas@ufpr.br 


\section{INTRODUÇÃO}

A adolescência é um período compreendido entre os 11 e 19 anos de idade, em que a jovem busca ativamente sua inserção na sociedade, por meio de sua descoberta do mundo, dos grupos, amizades e uma vida social mais vasta ${ }^{(1)}$. A gravidez na adolescência é considerada uma situação de risco para a saúde da criança e da jovem mãe, pois essas aderem menos ao programa do pré-natal e têm mais dificuldade para receber orientações com relação aos cuidados pessoais e do recém-nascido, aumentando a vulnerabilidade que envolve esse grupo ${ }^{(2)}$.

Estudos mostram que as principais causas de desmame precoce em adolescentes são as dificuldades para amamentar durante os primeiros dias, relacionadas à fissura mamilar, mastites, escassez do leite e dificuldade na pega, desconhecimento sobre a prática da amamentação, além de fatores como a existência de vida conjugal e a condição de ser estudante ${ }^{(3-4)}$. Trata-se de uma fase singular em sua vida devido às transformações presentes, adaptações ao novo corpo, adaptação ambiental e integração social. Sendo suas atitudes modificadas, devido a transição entre a infância e a vida adulta(5).

O aleitamento materno proporciona benefícios de saúde para mulheres e seus filhos, porém a prevalência da amamentação tem se mostrado mais baixa em mães adolescentes, em comparação com as mães idade mais avançadas ${ }^{(6-7)}$. As mães adolescentes constituem um grupo de risco para a continuidade do aleitamento materno, assim considera-se relevante o apoio familiar e social, para que estas jovens mães sintam-se estimuladas e consigam dar continuidade ao processo de amamentar ${ }^{(3,8-9)}$.

A prática da amamentação é diretamente influenciada por diferentes aspectos biológicos e pelas condições sociais da nutriz, como idade, escolaridade, condições de trabalho e vivência em sociedade, sendo esta última representada pelas redes de apoio social que a circunda ${ }^{(10)}$. O contexto sociocultural onde a mulher está inserida e a ansiedade com relação à amamentação resulta em prática complexa, a qual é influenciada pela vivência da nutriz em sociedade, permeada de mitos, crenças e valores repassados durante as gerações. Não devendo, portanto, ser apreendida simplesmente como uma função materna, mas de todos os indivíduos que cercam a nutriz ${ }^{(9)}$. Deste modo, a amamentação não deve ser vista apenas como um processo biológico, natural da condição materna, mas, como a percepção da mulher referente a si mesma, seu ambiente, e as suas relações com seu filho e demais integrantes de sua rede social|(11).

Esta rede social de apoio pode ser classificada em rede social de apoio primária e rede social de apoio secundária. Na Rede Primária, encontramse os familiares, pessoas próximas da lactante e o pai da criança. Por outro lado, a rede secundária compreende os profissionais da saúde que acompanham esta mulher durante os períodos pré e perinatal e puerperal ${ }^{(9)}$.

A rede social de apoio pode favorecer a prática do aleitamento materno, pelo incentivo e apoio à lactação, transmissão de conhecimentos e valores culturais, orientação quanto aos benefícios da amamentação, cuidados com criança e escuta ativa de suas demandas. Assim como pode prejudicar o mesmo pelo desinteresse, falta de estímulo à lactação e pela pressão à lactante em relação à forma de alimentação de seu filho ${ }^{(9,11-12)}$.

Destarte, é relevante conhecer a dinâmica destas redes sociais de apoio no contexto das nutrizes adolescentes, pois estas podem colaborar para o fortalecimento da promoção da saúde da criança e redução da morbimortalidade. Assim, tem-se como objetivo deste estudo investigar a influência das redes sociais de apoio no aleitamento materno de nutrizes adolescentes.

\section{MÉTODO}

Trata-se de uma pesquisa exploratória de abordagem qualitativa, realizada em um município da Região Metropolitana de Curitiba, em três Unidades de Saúde (US) com Estratégia de Saúde da Família (ESF), no período de setembro a outubro de 2011. As US foram escolhidas por possuírem o maior número de nutrizes adolescentes cadastradas no Programa SISPRENATAL da Secretaria Municipal de Saúde.

Participaram da pesquisa nove nutrizes, após aplicação dos critérios de inclusão: ser nutriz adolescente com idade de 10 a 19 anos quando no parto; possuir filho com até seis meses de idade na data da entrevista; e residir no território sob adscrição da ESF. Essas nutrizes foram selecionadas por meio 
do Programa SISPRENATAL da SMS das Unidades de Saúde com ESF de cada distrito administrativo com maior índice de adolescentes grávidas. Realizado esse primeiro levantamento, foi sorteado, juntamente com as enfermeiras, três puérperas adolescentes por US que foram entrevistadas em visita domiciliar, junto ao seu responsável legal.

Os dados foram coletados por meio de entrevista semiestruturada, sendo que o instrumento abordou aspectos como o tipo de alimentação da criança, duração do $\mathrm{AME}$, percepção da mãe quanto ao apoio recebido e o sentimento de amamentar seu filho, com vistas a questão norteadora deste estudo: qual a influência da rede social de apoio de nutrizes adolescentes no seu aleitamento materno?

As entrevistas foram transcritas, digitadas e interpretadas em concordância com o método de análise categorial temática. Da análise de dados emergiram duas categorias nominadas: Influência da Rede Social de Apoio Primária e Influência da Rede Social de Apoio Secundária.

Todas as participantes menores de 18 anos de idade tiveram o Termo de Assentimento assinado por elas e o Termo de Consentimento assinado pelos pais ou responsáveis; as maiores de 18 anos assinaram o TCLE. As participantes foram identificadas com a letra $M$ e numeradas sequencialmente, garantindo o anonimato. $\mathrm{O}$ projeto de pesquisa intitulado "Influências das Redes Sociais de Apoio no Processo de Amamentação de Nutrizes Adolescentes" está de acordo com os princípios de ética em pesquisa envolvendo seres humanos e foi aprovado pelo Comitê de Ética em Pesquisa da Universidade Federal do Paraná sob registro CAAE - 0099.0.091.091-11.

\section{RESULTADOS}

Para as nutrizes desse estudo os principais sujeitos envolvidos nos cuidados referentes à manutenção/promoção da alimentação da criança em seus primeiros meses de vida são elementos da família, vizinhos e os profissionais de saúde, hospital e maternidade, classificados aqui em Rede Social de Apoio Primária e Secundária.

\section{A Influência da Rede Social de Apoio Primária}

$\mathrm{Na}$ rede primária evidenciou-se a predominância do auxílio ofertado por elementos do gênero feminino e que, em sua maioria, já experenciaram a maternidade, entre eles as avós maternas e paternas:

Minha mãe [mãe da nutriz] que me ajuda bastante [...]. A minha sogra, ela mora ali, ela também ajuda [...]. (M 01)

Ela [mãe da nutriz] já teve 5 filhas, né [...] então eu já vou pela orientação dela. Ela já teve mais experiência [...] eles [rede primária] falam muita coisa, sabe, deixam a gente quase doido [...] daí a gente, eu venho, corro e pergunto pra minha mãe, né! (M 04)

Segundo as nutrizes a Rede Social de Apoio Primária desenvolve ações de apoio que influenciam no processo de amamentação, como o auxílio com as atividades domésticas, cuidados com o bebê e as orientações e intervenções relacionadas a problemas com a amamentação, conforme recortes dos depoimentos:

[a mãe] ajudava eu a dar banho, porque eu não sabia. (M01)

[a mãe] fazia tudo. Lavava roupa, fazia sopa, cuidava da neném pra eu tomar banho [...]. (M04)

Ela [prima do namorado] me ensinou o que muitas mães ensinaram, ela foi explicando tudo, que tem que fazer massagem antes de fazer esgotamento [para não ingurgitar] [...]. (M08)

Emergiram nos relatos as orientações que receberam dos membros da família que destoam das recomendações normativas do aleitamento materno:

Chegando em casa, a mãe [mãe da nutriz] colocou ela na mamadeira, daí é onde ela está agora [...]. (M04)

A minha madrasta falava que era bom [oferecer chá à criança], porque deixa a criança mais calma, [...] principalmente camomila e erva-doce e, também para, para cólica também, porque é bom [...]. E eu fiz [...] ela tem experiência, [...]. (M08) 
Aqui é um quintal, a família toda, e daí todas são mães, aí todas falam que é bom dar chá e aí eu dei [...]. (M08)

Oposto as influências positivas, as nutrizes também expressaram a influência negativa de alguns elementos da rede social de apoio no processo de amamentação. Este comportamento desperta nas adolescentes sentimentos de angústia, medo e insegurança advindos da prática da amamentação, exacerbando as dificuldades ao invés de diminuí-las como apresentado na fala a seguir:

Quando eu estava amamentado eu já não tinha bico, daí ficavam em cima querendo pegar... eu acho que eu ficava nervosa, sabe, daí eu não tinha como [...] amamentar meu filho[...] [a sogra dizia] que estava errado! (M03)

\section{A Influência da Rede Social de Apoio Secundária}

Na rede secundária, os elementos de apoio às nutrizes são representados pelo serviço de saúde primário (US) e terciário (maternidade local e hospital maternidade), também referenciados pelo apoio ofertado pelos médicos, enfermeiros e agentes comunitários de saúde, como exemplos a seguir:

Quando eu preciso ali [da Unidade de Saúde] eles me ajudam, sabem, eles, nossa, eles me ajudam bastante ali [...] Uma enfermeira me orientou ali no posto. (M 03)

Na maternidade falaram, assim como no postinho também [sobre a amamentação]. (M 07)

As principais ações identificadas como apoio às famílias ofertadas pela Rede Social de Apoio Secundária foram, a educação em saúde e o auxílio direto no cuidado com o bebê, mediante ajuda para a pega correta nas primeiras mamadas e nas consultas de puericultura.

Foi o pessoal mesmo da parte de enfermagem, mesmo, ali do posto [quem orientou sobre amamentação, intercorrências, cuidados com o bebê] [...]. (M03)
Ah, sempre tem, no pré-natal eles vão falando, mandam a gente ir fazendo o bico no seio, $e$ tem que dá mamá porque é bom pra criança, pra mãe [...]. (M01)

[...] elas [enfermeiras] falaram que é pra passar o próprio leite do peito [...]. Teve palestra! [...] eu participei aqui no posto... e na maternidade [...] eles sempre vinham orientando [...]. (M06)

Também foram identificadas ações de estímulo à continuidade do aleitamento materno, principalmente no domínio da US, por meio das quais os profissionais estimulam a interrupção da oferta da mamadeira e retorno ao seio materno:

Eles [equipe das US] falaram que era para eu continuar estimulando ele, por mais que às vezes ele não pegasse, que era para deixar ele com bastante fome para ele pegar [o seio] [...]. (M02)

Quando eu cheguei lá e falei que meu filho estava na mamadeira, eles falaram assim que era para eu tentar ainda [...] me ensinaram um exercício [para formar o bico do seio] daí eu fui fazendo [...]. (M03)

Percebe-se ainda que formas inapropriadas de intervenções realizadas por alguns profissionais instigaram sentimentos como insatisfação quanto às orientações e insegurança no momento da realização dos cuidados com o bebê, como observado:

O ruim é que elas ficavam achando que eu é que não queria dar o mamá pra neném [...] eles ficavam brigando, daí eu pegava e ficava desesperada, lá [maternidade], porque a bebê não mamava, também [...] e elas brigando [...]. (M01)

Ah, eles falam "mãe, não pode fazer isso!" "mãe, não pode fazer aquilo!" [...]. (M04)

Algumas mães, quando questionadas sobre o apoio recebido pelos profissionais de saúde diante das situações de dificuldade enfrentadas no início da amamentação, demonstraram descontento: 
Uma enfermeira até falou, "ah! è que você não tem vontade, é que você não quer dar de amamentar [...]. (M02)

\section{É [...] só que entregava só o papel, assim} [...] um papelzinho e perguntavam se estava amamentando, mais essas perguntas, assim e já saíam. Não explicavam muita coisa [...]. (M08)

Analisando as entrevistas identificou-se que as nutrizes que relataram maior vínculo com a rede secundária apresentaram maior conhecimento sobre o tema aleitamento materno e consequentemente amamentaram por mais tempo.

\section{DISCUSSÃO}

O reconhecimento da rede social de apoio à nutriz adolescente possibilita ao profissional de saúde ampliar seu escopo para planejar suas ações envolvendo no cuidado, pessoas influentes na vida das nutrizes adolescentes.

Emergiram neste estudo como principais elementos de apoio a amamentação, os familiares que durante esta fase da vida tendem a estarem mais presentes no cotidiano das jovens mães auxiliando no cuidado com o bebê e atividades domésticas. A família como elemento da Rede Social de Apoio Primária, possui importância fundamental no cuidado aos seus membros, considerada o primeiro espaço de socialização do indivíduo, onde ele desenvolve os primeiros conceitos do meio que o cerca, bem como sua identidade social ${ }^{(13)}$.

Cabe ao familiar mais próximo a função de equilibrar a dinâmica familiar, auxiliando nos cuidados com o bebê e nas atividades domésticas, além de informar e confortar, oferecendo também o apoio necessário para o equilíbrio psicológico e emocional da nova mãe $\mathrm{e}^{(11)}$.

Entre os elementos da rede primária, nesse estudo, foram citadas as avós, maternas e paternas, irmãs e primas, principalmente as mulheres que já passaram pelas mesmas experiências. Essas expressaram medos, aflições e a influência cultural, baseada nos saberes e valores populares, presente na escolha da alimentação da criança. Estes valores, embora aceitos pelas mães, eventualmente contrariam as orientações do Ministério da Saúde, sobre amamentação e cuidados com o bebê, o que pode levar ao estabelecimento de conflitos entre o saber profissional e o popular. Quando vivencia a maternidade, a mulher torna-se mais suscetível às influências externas, principalmente no que se refere aos cuidados com o bebê e a amamentação(14).

Em qualquer processo de mudança sofrido por determinado indivíduo, especialmente na fase da adolescência, a família exerce papel ativo nas decisões que são tomadas. No processo da amamentação, isso acontece de forma semelhante, uma vez que interfere diretamente no cuidado com o bebê, no auxílio com as atividades pertinentes ao cotidiano da mulher ou à pressão que esta nutriz encontra-se exposta, contribuindo para a sua qualidade e duração ${ }^{(9)}$.

A figura da avó da criança torna-se a mais importante para a nutriz durante o aleitamento materno ${ }^{(9)}$, representando uma das mais notáveis fontes de apoio à nutriz na fase da lactação, podendo exercer uma influência positiva ou negativa sobre a manutenção do aleitamento ${ }^{(15)}$. Por vezes, as nutrizes deste estudo relataram orientações de familiares que podem ser indutoras ao desmame precoce, bem como orientações de introdução de alimentação complementar inadequada. Portanto, nas situações em que a nutriz se percebe sem apoio, contribuem no incentivo ao desmame precoce, especialmente quando as dificuldades enfrentadas por esta mãe não são compreendidas pelos familiares ${ }^{(11)}$. Os conhecimentos e experiências vividas por outros membros da família são repassados à nova mãe como conselhos, exemplos e ensinamentos, preservando-se, os costumes inerentes ao grupo ${ }^{(16)}$. Porém, deve-se lembrar de que as avós têm influência no processo de amamentação devido às experiências pessoais, salienta-se que durante muitos anos era correto oferecer leite artificial, sopas, chás, mingaus, ao invés de aleitamento materno natural, assim estas influências podem trazer prática promotoras do aleitamento materno ou indutoras ao desmame precoce.

Portanto, é preciso repensar as práticas de promoção do aleitamento materno, na perspectiva de incluir o membro da rede social de apoio primária nesta prática, devendo-se envolvê-lo na preparação da gestante para a lactação, extrapolando inclusive o período pré-natal, envolvendo-o 
também no seguimento em puericultura, reforçando orientações, desmistificando conceitos e crenças que podem prejudicar a adesão e manutenção do aleitamento materno ${ }^{(14)}$.

As adolescentes citaram os profissionais de saúde como o segundo grupo de maior influência no apoio e incentivo ao aleitamento materno. Estudos sobre amamentação trazem a importância da rede secundária para a promoção do aleitamento materno. O profissional de saúde deve ser capaz de desenvolver laços estreitos com a nutriz, para que possa desempenhar um papel de auxílio e incentivo à promoção da saúde da nova mãe e de seu bebê, especialmente com relação ao aleitamento materno ${ }^{(2)}$. Para tanto a atuação deste profissional pode ocorrer em diferentes etapas, desde o período pré-gestacional ao puerpério, quando este é efetivo, a gestante adolescente sente-se mais segura e qualificada para realizar o cuidado com o filho de forma mais adequada. $\mathrm{O}$ papel da educação em saúde para a promoção do aleitamento materno mostra-se fundamental ${ }^{(17)}$.

A mãe deve sentir-se segura e confiante nos cuidados com seu filho, deve acreditar que é capaz de suprir todas as suas necessidades. Para que isso aconteça, o profissional deve possuir competência para auxiliar a mãe em todas as dificuldades, buscando constantemente informar, apoiar e incentivar ${ }^{(17)}$. Porém, em algumas falas as nutrizes demonstraram insatisfação com a atuação de alguns profissionais apresentaram práticas prescritivas, impuseram suas opiniões causando dúvidas e inseguranças. É fundamental para o profissional de saúde conhecer a realidade de vida da nutriz, e após esta etapa estabelecer um plano de ações para o incentivo do aleitamento materno que esteja de acordo com a realidade encontrada. Ações baseadas exclusivamente em pressupostos e ideias pré-concebidas, desenvolvidas de forma impositiva tornam a assistência ineficaz. Torna-se necessário que o cuidado seja baseado na empatia, sem preconceitos ou pressupostos, adequando-se às condições em que se encontra a mãe ${ }^{(18)}$.

\section{CONSIDERAÇÕES FINAIS}

A Rede Social de Apoio Primária e Secundária da nutriz adolescente caracterizou-se por familiares e profissionais da saúde das Unidades
Básicas de Saúde e das maternidades. Sendo assim, a influência e o apoio de indivíduos próximos a ela e dos profissionais de saúde de todos os níveis de atendimento torna-se fundamental para a promoção da saúde do lactente.

A influência dos familiares na adesão e manutenção do aleitamento materno sofre alterações de fatores sociais e culturais que passam de geração para geração. Evidencia-se a importância do papel educativo no pré-natal pelos profissionais de saúde e a necessidade de capacitá-los no manejo da amamentação para auxiliar as nutrizes adolescentes a superarem as dificuldades encontradas nesse processo.

Para tanto, torna-se necessário que a equipe de enfermagem proporcione um apoio contínuo às gestantes adolescentes durante o pré-natal e no período pós-parto, por meio de estratégias como participação em grupos, visitas domiciliares, inclusão das avós e outros membros da família nas orientações, a fim de que seja garantida a continuidade das ações de promoção do aleitamento materno.

Considerando-se a importância do apoio das redes primária e secundária, e a magnitude com que cada um deles interfere no processo de amamentação da nutriz adolescente, ressalta-se a importância da ligação entre os profissionais de saúde, a lactante e sua família, a fim de fortalecer vínculos, interligar conhecimentos e articular ações de promoção e proteção à prática do aleitamento materno, de maneira adequada à realidade de cada nutriz.

\section{REFERÊNCIAS}

1. Martinez EZ, Roza DL, Caccia-Bava MCGG, Achcar JA, Dal-Fabbro AL. Gravidez na adolescência e características socioeconômicas dos municípios do Estado de São Paulo, Brasil: análise espacial. Cad. Saúde Pública. 2011;27(5):855-67.

2. Santos LC, Ferrari AP, Tonete VLP. Contribuições da Enfermagem para o Sucesso do Aleitamento Materno na Adolescência: revisão integrativa da literatura. Cienc. cuid. saude. 2009;8(4):691-8.

3. Nelson A, Sethi S. The Breastfeeding Experiences of Canadian Teenage Mothers. J. Obstet. Gynecol. Neonatal Nurs. 2009;34(5):615-24.

4. França GVA, Brunken GS, Silva SM, Escuder MM, 
Venancio SI. Determinantes da amamentação no primeiro ano de vida em Cuiabá, Mato Grosso. Rev. Saúde Públ. 2007;41(5):711-8.

5. Mazzini MLH, Alves ZMMB, Silva MRS, Sagim MB. Mães adolescentes: a construção de sua identidade materna. Cienc. cuid. saude.2008;7(4):493-502.

6. Ministério da Saúde (BR). II Pesquisa de prevalência de aleitamento materno nas capitais brasileiras e Distrito Federal. Brasília, 2009.

7. Grassley JS. Adolescent Mothers' Breastfeeding Social Support Needs. J. Obstet. Gynecol. Neonatal Nurs. 2010;39(6):713-22.

8. Wambach KA, Cohen SM. Breastfeeding Experiences of Urban Adolescent Mothers. J. pediatr. nurs. 2009;24(4):244-54.

9. Grassley JS. Adolescent Mothers' Breastfeeding Social Support Needs. J. obstet. gynecol. neonatal nurs. 2010;39(6):713-22.

10. Marques ES, Cotta RMM, Magalhães KA, Sant'Ana LFR, Gomes AP, Siqueira-Batista R. A influência da rede social da nutriz no aleitamento materno: o papel estratégico dos familiares e dos profissionais de saúde. Ciênc. saúde colet. 2010;15(S1):1391-400.

11. Junges CF, Ressel LB, Budó MLD, Padoin SMM, Hoffmann IC, Sehnem GD. Percepções de puérperas quanto aos fatores que influenciam o aleitamento materno. Rev. Gaúcha. Enferm. 2010;31(2):343-50.

12. Müller FS, Silva IA. Social representations about support for breastfeeding in a group of breastfeeding women. Rev. Latino-Am. Enfermagem. 2009;17(5):651-7.

13. Ladomenou F, Kafatos A, Galanakis E. Risk factors related to intention to breastfeed, early weaning and suboptimal duration of breastfeeding. Acta Paediatr. J. 2007;96(10):1441-4.

14. Teixeira MA, Nitschke RG, Silva LWS. A prática da amamentação no cotidiano familiar um contexto intergeracional: influência das mulheres-avós. Rev. kairós. 2011;14(3):205-21.

15. Barreira SMC, Machado MFAS. Amamentação: compreendendo a influência do familiar. Ciênc. saúde colet. 2004;26(1):11-20.

16. Susin LR, Giugliani ERJ, Kummer SC. Influência das avós na prática do aleitamento materno. Rev. Saúde Públ. 2005;39 (2):141-7.

17. Frota MA, Mamede ALS, Vieira LJES, Albuquerque CM, Martins MC. Práticas culturais sobre aleitamento materno entre famílias cadastradas em um programa de saúde da família. Rev Esc Enferm USP. 2009;43(4):895901.
18. Sepka GCS, Gasparelo L, Silva ABF, Mascarenhas TT. Promoção do aleitamento materno com mães adolescentes: Acompanhando e avaliando essa prática. Rev. Cogitare enferm. 2007;12(3):313-22. 